\title{
Pollen competition reduces inbreeding depression in Collinsia heterophylla (Plantaginaceae)
}

\author{
A. LANKINEN*, $\uparrow \& W$. S. ARMBRUSTER $R^{*} \ddagger$, \\ *Department of Biology, Norwegian University of Science and Technology, Trondheim, Norway \\ $\dagger$ Department of Plant Ecology and Systematics, Lund University, Ecology Building, Lund, Sweden \\ $\$$ Institute of Arctic Biology and Department of Biology and Wildlife, University of Alaska, Fairbanks, AK, USA \\ $\S$ School of Biological Sciences, University of Portsmouth, King Henry Building, Portsmouth, UK
}

Keywords:

mating-system evolution; mixed-mating system;

pollen-load size;

prezygotic selection;

self-pollination.

\begin{abstract}
We tested two predictions of the hypothesis that competition between selfpollen may mitigate negative genetic effects of inbreeding in plants: (1) intense competition among self-pollen increases offspring fitness; and (2) pollen competition reduces the measured strength of inbreeding depression. We used Collinsia heterophylla (Plantaginaceae), an annual with a mixed mating system, to perform controlled crosses in which we varied both the size of the pollen load and the source of pollen (self vs. outcross). Fitness of selfed offspring was higher in the high pollen-load treatment. Our second prediction was also upheld: inbreeding depression was, on average, lower when large pollen loads were applied $(11 \%)$ relative to the low pollen-load treatment $(28 \%)$. The reduction was significant for two fitness components relatively late in the lifecycle: number of surviving seedlings and pollen-tube growth rate in vitro. These findings suggest that intermittent inbreeding, which leads to selffertilization in plants with genetic loads, may select for traits that enhance pollen competition.
\end{abstract}

\section{Introduction}

The evolution of closed carpels, unique to the flowering plants, created the opportunity for competition between pollen for access to ovules (Carr \& Carr 1961; Endress 1982; Armbruster et al. 2002a). In a highly influential paper, Mulcahy (1979) suggested that because pollen is haploid, pollen competition may be an important way to screen against inferior genomes. During the last 25 years numerous investigations have explored the functional and evolutionary significance of pollen competition (e.g. Marshall \& Ellstrand 1986; Winsor et al. 1987; Quesada et al. 1993; see reviews in Mulcahy \& Mulcahy 1987; Willson, 1994; Skogsmyr \& Lankinen 2002). Traditionally, studies tested whether more intense competition resulted in increases in offspring fitness, assuming overlapping gene expression in gametophytes and sporo-

Correspondence: Å. Lankinen, Department of Plant Ecology and Systematics, Lund University, Ecology Building, 22362 Lund, Sweden.

Tel.: +46 46 2229293; fax: +46 46 2224423;

e-mail: asa.lankinen@ekol.lu.se phytes (Mulcahy et al. 1992; Walsh \& Charlesworth 1992; Hormaza \& Herrero 1994, 1996). Although offspring fitness was often improved (e.g. Mulcahy $\delta$ Mulcahy 1975; Winsor et al. 1987; Bertin 1990; Quesada et al. 1993), the experimental design of these studies did not make it possible to separate between various selection pressures on pollen competitive ability vs. gynoecial traits that enhance pollen competition (e.g. long pistils) (Charlesworth et al. 1987; Snow 1994). In more recent years, the focus has shifted towards testing how selection during pollen competition can reduce inbreeding in self-incompatible species (Charlesworth et al. 1987; Cruzan 1990; Paschke et al. 2002; Stephenson et al. 2003), or how selection acts on male and female reproductive functions (sexual selection) (reviewed in Skogsmyr \& Lankinen 2002).

Thus far, most research on pollen competition has focused on processes that promote fertilization by genetically superior or compatible sporophyte (diploid) fathers. Because the pollen loads on stigmas do often contain a mixture of pollen from different genetic individuals (Snow 1994), it is likely that competition 
occurs between pollen donors. Competition among related pollen grains is, however, also conceivable (Bernasconi et al. 2004). Such competition might in fact be of particular importance in plants that self or have mixed mating systems, because pollen loads will comprise pollen from only one individual (self-pollen) when pollinators fail to visit. As hypothesized in a recent paper by Armbruster \& Rogers (2004), pollen competition between self-pollen might be of significance because this allows screening of defective haploid genomes. This should mitigate the negative effects of self-pollination because it reduces the probability of producing offspring with homozygous recessive deleterious alleles (i.e. reduces inbreeding depression under the partial dominance model; Charlesworth \& Charlesworth 1987; inbreeding depression is defined as the reduced fitness of inbred progeny relative to those derived from outcrossing). Since pollen and ovules produced by the same plant may share many recessive deleterious alleles, the fitness of selfed sporophytic offspring would thus be expected to increase with the intensity of pollen competition when such competition can prevent offspring receiving two copies of these alleles.

Mixed mating systems are common, at least among insect-pollinated species (Vogler \& Kalisz 2001), although some theoretical work indicates that plants should either be completely selfing or completely outcrossing (Lande \& Schemske 1985; Schemske \& Lande 1985; but see below). The underlying reason for this theoretical conclusion is that outcrossing populations are assumed to maintain deleterious alleles, whereas in selfing populations the strong selection against deleterious alleles will eventually lead to their being purged out of the population. Unlike selfers then, outcrossing populations should experience strong inbreeding depression, which will maintain outcrossing. In the absence of inbreeding depression, selfing will be favoured because selfers transmit two gene copies per offspring rather than one to the next generation (Fisher 1941). Intermediate mating systems can, however, be stable when there is spatial and temporal variation in pollination intensity (Lloyd 1979; Lloyd \& Schoen 1992; Tsitrone et al. 2003), in inbreeding depression (Cheptou \& Mathias 2001) or when factors (like pollen competition) conditionally mitigate inbreeding depression (Armbruster \& Rogers 2004; see below). Variation in pollination intensity is known to be common (Bierzychudeck 1981; Snow 1982; Burd 1994; Wilson et al. 1994; (Herrera, 2002, 2004). Self-compatible plants growing in populations where pollinator abundance is variable will often experience a combination of outcrossing and selfing within or between years, and as a result, deleterious alleles (genetic load) can persist in such populations. Thus, such populations may both harbour genetic load and self-fertilize frequently, and hence experience frequent inbreeding depression. In this situation, selection should favour traits that reduce inbreeding depression, at least if there is any variation for such traits.

To study if intense pollen competition can reduce negative effects of self-pollination, we performed controlled crosses in Collinsia heterophylla. This species is known to have a mixed mating system (Charlesworth $\&$ Mayer 1995; Armbruster et al. 2002b). We varied both pollen-load size and pollen source (self vs. outcross), in order to test two predictions of the hypothesis that pollen competition mitigates negative effects of selfpollination (Armbruster \& Rogers 2004). First, we predicted that the quality of selfed offspring is improved by pollen competition; we therefore analysed offspring fitness produced by self-pollination under high vs. low pollen competition. Secondly, we predicted that the measured strength of inbreeding depression should be reduced by pollen competition; we therefore compared inbreeding depression at two levels of pollen competition.

The key distinction between our two predictions is that in the second one we were able to test whether fitness effects of pollen load differ between outcross and selfed treatment. It is important to note that, although the two predictions are not independent, the second is the more explicit test of the hypothesis that pollen competition can reduce the cost of inbreeding by improving fitness of selfed offspring. If the second prediction holds true, the first prediction will automatically hold as well. The reverse is not the case, however, and prediction one is, in fact, a weaker test of the same hypothesis. Tests of the first prediction do not tell us how fitness of selfed offspring is improved by pollen competition relative to fitness of outcrossed offspring, and thus cannot provide sufficient evidence to rule out other causes. For example, improvement of offspring fitness by competition between self-pollen could be the result of eliminating inferior additive alleles through pollen competition rather than the elimination of recessive deleterious alleles, as required by the inbreeding-depression hypothesis (Armbruster $\&$ Rogers 2004). The present study provides a stronger test of the inbreeding-depression hypothesis than previous studies because it examines the more-restrictive prediction. We also include a test of the weaker prediction (prediction 1), however, because its statistical analysis is more straightforward, and in order to allow comparisons with earlier studies that evaluated (and supported) only prediction 1 (see Armbruster \& Rogers 2004, and references cited therein).

Thus, direct comparisons of the amount of inbreeding depression with and without intense pollen competition are needed to test fully the hypothesis that pollen competition affects the level of inbreeding depression. In testing this restrictive prediction, the current study provides the strongest direct support of the hypothesis that inbreeding depression is reduced by pollen competition. 


\section{Materials and methods}

\section{Study species}

Collinsia heterophylla Buist (Plantaginaceae) is a diploid annual native to the California Floristic Province (Newson 1929; Neese 1993). The species is widely distributed and flowers between March and June depending on latitude and elevation. The species is self-compatible with outcrossing rates estimated to rage from 0.32 to 0.64 , based on allozyme markers of several populations (Charlesworth \& Mayer 1995). Plants are pollinated by a variety of native bees (Armbruster et al. 2002b; W.S. Armbruster, unpublished data). Flowers are zygomorphic, with a five-lobed corolla arranged in one upper and one lower lip. Flowers have four epipetalous stamens and one pistil, containing up to 16 ovules (Armbruster et al. 2002b). At the time of flower opening, anthers are undehisced and the stigma is not receptive; this makes experimental emasculation of the flowers easy. Over the course of 3-4 days, the anthers dehisce usually one at a time. During this period the stigma becomes receptive and the style elongates. This eventually places the stigma in contact with the dehisced anthers, and self-pollination can occur (see Armbruster et al. 2002b for a more detailed description; see also Kalisz et al. 1999). Flowers are arranged in whorls on spikes. Corolla colour is generally white to pale purple on the upper lip and dark purple on the lower lip, although some populations can be dark on parts of the upper lip and others pale purple or off-white on both lips. Ovaries develop into dry, dehiscent seed capsules.

Plants used in our experiment were collected as seeds from a population in Sesar Canyon, Ventura County, California (approximately 40 maternal families) (population 4 in Armbruster et al. 2002b). Flowers in this population are of the off-white (upper lobe)/pale-lavender (lower lobe) form.

\section{Crossings}

We performed crosses in an insect-free greenhouse to assess if higher levels of pollen competition can reduce the negative effects of inbreeding. On a total of 39 recipient plants, we conducted four types of pollinations per recipient: (1) self-pollen, low pollen load; (2) selfpollen, high pollen load; (3) outcross pollen, low pollen load; and (4) outcross pollen, high pollen load. All four pollinations were made on the same day. To reduce potential effects of differential allocation of maternal resources between flowers (Charlesworth 1988; see below), the four crosses were conducted on flowers in separate inflorescences. No crosses were made on the first inflorescence (main stem).

It has been suggested that differences in progeny vigour following pollen competition can be the result of differential provisioning by the maternal plant
(Charlesworth 1988; Walsh \& Charlesworth 1992; Delph et al. 1998). To test for an allocation effect, we conducted a second experiment in which we pollinated four flowers adjacent to the first crossed flowers (always in the same inflorescence). These crosses were made on the following day. All four second pollinations on an individual were of the same type (one of types 1-4 above). If allocation between flowers is important for offspring fitness, we should see an effect of the identity of the neighbouring second cross. By carefully controlling our crosses for time and space, we were able to study effects of both pollen competition and allocation. However, this design did not permit repeated crosses on the individual recipients.

Crosses were made on previously emasculated flowers 4 days after flower opening. At this stage, stigmas are fully receptive (Armbruster et al. 2002b). Pollen from two to three flowers was mixed on microscope slides. For outcross pollen, we used a mixture of the same three pollen donors (one flower from each). These donors differed in pollen-tube growth rate in a germination medium (one-way ANova; $F_{2,28}=5.99, P=0.0071$ ). Pollen was applied to the stigma directly from the slide. Small pollen loads were controlled for by counting pollen grains under the microscope before and after application. The average number of pollen grains applied on the stigma in the small pollen load was 13.6 ( $\mathrm{SE}=0.199$, minimum $=10$, maximum $=22, n=158$ ). For the large pollen-load treatment enough pollen was applied to cover the stigma completely with one layer of pollen grains. This was estimated to be about 50 pollen grains. Seeds were collected when capsules were ripe (after approximately 3-4 weeks). Capsules were bagged after 2-3 weeks to avoid losing seeds. The number and weight of seeds per capsule was determined.

In a separate experiment, we made crosses to estimate the number of pollen grains needed for full seed set. On each of the eight recipients used we made at least 20 crosses with either outcross or self-pollen (10 of each). The source of outcross pollen was a mixture of the same three donors. In most crosses, we varied the number of pollen grains from very few to nearly covering stigma $($ minimum $=2$; maximum $=$ 38), using the technique described above. In a few crosses, the stigma was completely covered with pollen (equals the large pollen load treatment, approximately 50 pollen grains). The pollen saturation-curve suggests that seed set is still increasing from the low to the high pollen load used in our experiment (Fig. 1). Individual differences in seed set are probably the reason for not finding a stronger relationship between the pollen-load treatment and seed set. Although this might imply that the effect of pollen competition might be concealed in individuals with a low maximum seed set, average seed set for our low and high pollen load treatments is in fact clearly different (2.3 vs. 4.7). The small pollen load treatment should thus be small enough to where seed 


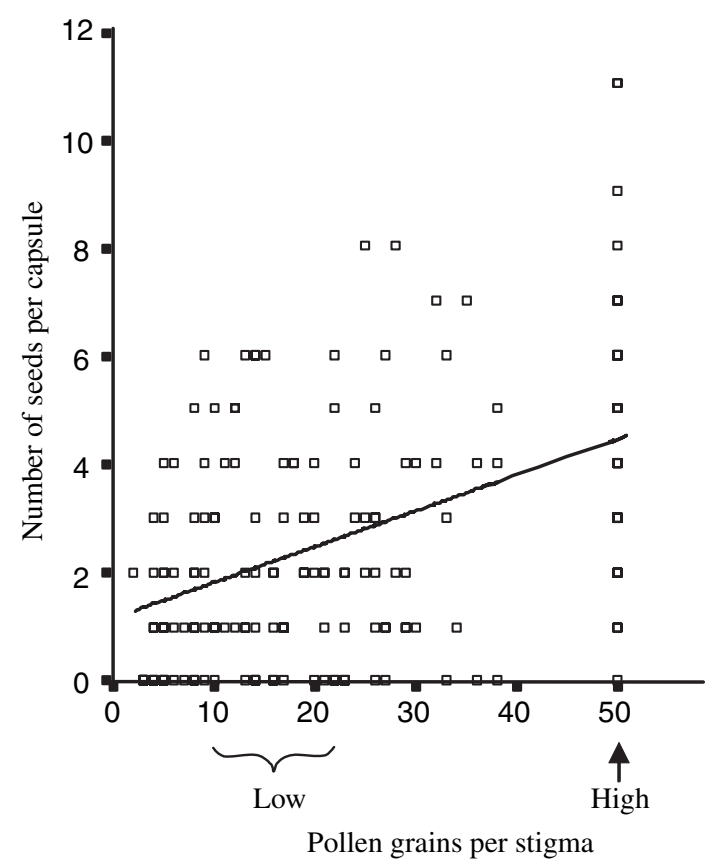

Fig. 1 Number of seeds per capsule increases with number of pollen grains on the stigma. The data can be described by a linear relationship: seed set $=1.05+0.69 \times($ pollen $/$ stigma $) ; R^{2}=0.21$, $P<0.0001$. The data can also be described by a nonlinear relationship where the increase is highest for lower pollen loads and levels off towards a completely covered stigma (high). Seed set $=$ $-0.94+1.26 \times \ln$ (pollen/stigma); $R^{2}=0.19, P<0.0001$. The fit to the data was marginally better for the straight line. The low and high pollen load treatments used in our experiment corresponds to 'low' $(\bar{x}=13.6)$ and 'high' (ca. 50 pollen grains) respectively. Outcrossed and selfed flowers were pooled together. $N=174$ flowers.

set increases with additional pollen (Mitchell 1997). Therefore, our pollen load treatments should be adequately different, and be in the 'filling region', i.e. we should expect more pollen competition in the high pollen load treatment than in the low pollen load treatment.

\section{Measurements of offspring fitness}

In order to determine the relative fitness of selfed and outcrossed progeny from the two pollen-load treatments, various offspring-fitness traits, both early and late in life, were assessed. Seeds were sown and kept in a refrigerator for approximately a week to break seed dormancy. Seeds started to germinate 1 day after they had been placed in the greenhouse $(16 \mathrm{~h}$ day, about $25^{\circ} \mathrm{C}$ by day, $15{ }^{\circ} \mathrm{C}$ by night). Most seed germination took place during the following 3 days. After approximately a week no more seeds germinated. Total germination percentage, and number of surviving seedlings 4 weeks after sowing were recorded. Since most plants survived to week 4, we were not able to analyse seedling survival separately. Instead, we assessed an integrative measurement of number of surviving seedlings: number of seeds produced times seed germination times survival to week 4 . At the age of 4 week, three offspring per treatment, per recipient were kept for measurements of later fitness components. Two weeks after the date of first flowering (for each individual), the number of flowers in the first inflorescence (main stem) was measured.

To evaluate pollen competitive ability, we germinated pollen in Hoekstra germination medium (Hoekstra $\delta$ Bruinsma 1975). Pollen from two flowers per individual was sprinkled sparsely onto a drop of medium (pollen performance was reduced with too high a pollen density). Pollen was allowed to germinate in a dark chamber at a steady temperature of $22{ }^{\circ} \mathrm{C}$ for $1.5 \mathrm{~h}$. All individuals in a family-group (the same mother) were germinated at the same time. To estimate average pollentube growth rate of an individual, we measured pollentube length of the first 10 tubes encountered in the microscope view. The average length of the tubes was used for further analyses.

In this species, pollen tube growth rate in germination medium correlates with pollen tube growth rate in the pistil (Pearson correlation; $r_{20}=0.481, P=0.032 ; \AA$. Lankinen and W.S. Armbruster, unpublished data). Since it was only possible to measure one pollen tube per sample in the pistil (the longest), noise and measurement error in vivo were probably large. This might explain why the relationship between in vitro and in vivo pollen tube growth rate was not stronger.

\section{Selection of offspring-fitness traits examined}

We chose to examine offspring traits that we believed to be most independent and reliable indicators of fitness while allowing analysis of effects from different stages of the plant life cycle. We did not include speed of germination (or seedling size or start of flowering) partly because how fast a seed germinates in this species is probably also connected to how fast seed dormancy is broken. Germination has been found to extend over a period of 3 weeks in a refrigerated growth chamber (Å. Lankinen, personal observation). Furthermore, speed of seed germination can be influenced by many random factors and may not be independent of seed size, because the speed can decline with decreasing surface area to volume ratios (Whittington \& Fierlinger 1972; Prinzie \& Chmielewski 1994; Khan et al. 1999). Days to flowering might also be misleading, because stressed plants often start flowering earlier (Bernier et al. 1993; Adams et al. 1998). The relationship between these two traits and offspring fitness might therefore not be linear. We regarded number of flowers as a better assessment of plant vigour than seedling size or final vegetative size because it is more directly related to fitness. 


\section{Statistical analyses}

Differences in fitness of selfed offspring between the two pollen-load treatments (our first prediction) were tested with a mixed-effects GLM, including recipient plant as a random factor and pollen load as a fixed factor. To test for the overall significance of all tested fitness traits we used a doubly multivariate within-subject design [i.e. a MANOVA that controls for using the same recipient plants for all treatments (Hill \& Lewicki 2006)] with pollen load as the testing factor.

We analysed whether the degree of inbreeding depression differed between the pollen load treatments (our second prediction) with a mixed-effects general linear model (GLM). In the model, we included recipient plant as a random factor, and pollen load and crossing type as fixed factors. Because we wanted to compare the ratio rather than the difference between selfed and outcrossed offspring in the two pollen load treatments (see Charlesworth \& Charlesworth 1987), the data were log-transformed. Transformation of data to a logarithmic scale makes the ratios additive and thus appropriate for testing the difference between pollen-load treatments (as indicated by a significant crossing-type-by-pollen-load interaction; Johnston \& Schoen 1994). In some instances seed capsules were aborted. This did not happen often enough to allow us to analyse this trait separately. To ensure that we did not underestimate inbreeding depression (Lande et al. 1994; Husband \& Schemske 1996) we included aborted capsules as zeros. To be able to log-transform data containing zeros we added 0.1 or 0.01 to all values, depending on the magnitude of the variable. We also confirmed that the results were consistent when other values were added (both larger and smaller). In addition, in all analyses the proportion of seeds germinated was arcsine-transformed to obtain a normally distributed data set (Sokal \& Rohlf 1995).

To test the overall significance of changes in inbreeding depression with pollen load, we used a one-tailed binomial test (Siegel \& Castellan 1988) to investigate whether there were significant crossing-type-by-pollenload interactions in more fitness components than was expected by chance. The two categories are (1) significant interactions; and (2) nonsignificant interactions. We used a one-tailed test because we predicted in advance that the category 'significant interactions' should apply to more fitness traits than expected under the null hypothesis. The null hypothesis is that inbreeding depression does not differ between pollen load treatments. We should then only find significant differences in the proportion of all cases that equals our significance level for the separate tests. Taking both the significance levels of $p=0.05$ and $p=0.001$ into account, we calculate the probability to obtain exactly a particular number of significant values with certain significance levels, $P$, as

$$
P=\frac{N !}{n 1 ! n 2 !(N-n 1-n 2) !}(p 1-p 2)^{n 1} p 2^{n 2}(1-p 1)^{N-n 1-n 2},
$$

where $N$ is total number of variables tested, $n l$ is the number of variables significant at the level of $p 1$ and $n 2$ is the number of variables significant at the level of $p 2(p 1=0.05>p 2=0.001)$. To calculate the probability of getting our observed result (frequency of significant interactions) assuming $H_{0}$ is true, we added the probability of the observed outcome to the probabilities for all other possible outcomes that were more extreme than that observed.

We also tested overall significance with a doubly multivariate within-subject design, including the factors pollen load, crossing type and their interaction. The advantage of a MANOvA is that correlations among variables are taken into account. On the other hand, the power of a MANOva to detect effects that genuinely exists is dependent on both intercorrelation among traits as well as size and patterns of group differences (Field 2005). For example, power can be lowered if not all group differences are in the same direction for each measure. Since the expression of early acting inbreeding depression has been shown to differ from that of late acting inbreeding depression (Husband $\delta$ Schemske 1996), we evaluated fitness components from early vs. late life-cycle stages in two separate manovas. This also allowed us to ask whether inbreeding depression between high- and low-pollen loads was affected differently affected by early and late life-cycle stages. The division of our variables into two groups might be somewhat arbitrary for variables that are not strictly early (seed production) or strictly late (growth and reproduction), e.g. germination and survival. However, only considering seed traits as the early fitness components did not change the outcome of the analyses.

To quantify inbreeding depression, we standardized the difference in the mean between selfed and outcrossed offspring by the mean of outcrossed progeny, $\delta$ (Charlesworth \& Charlesworth 1987).

To test for an effect of allocation of maternal resources, we used a fixed-effects GLM with the factors, crossing type, pollen load and neighbouring cross. We were not able to analyse allocation effects on pollen tube growth rate, since this trait was only measured in ten maternal families. Due to the low $n$ value per allocation group (two or three), allocation group could not be adequately separated from effects of maternal family.

ANOVAS were performed using SPSS (SPSS 1999) and MANOVAS were made in statistica (2005). Type-III sums of squares were used in all Anovas and type-VI sum of squares were used in all manovas. The measure of association in the MANOvAs was assessed with Wilks' lambda. 


\section{Results}

\section{Offspring fitness under high and low pollen competition}

According to our first prediction, fitness of selfed offspring should be lower in the low pollen-load treatment than in the high pollen-load treatment. Since the number of seeds produced in the two treatments may be influenced by pollen limitation to some degree, no fitness components involving this variable were considered. Pollen-tube growth rate in individuals produced under low-pollen loads was significantly lower than under high-pollen loads (Fig. 2g, Table 1). In the other three investigated fitness components there were nonsignificant trends in the expected direction (Fig. 2b,d,f; Table 1). The effect of pollen load treatment was significant when analysing all four variables in a MANOvA (within-subject MANOvA; pollen load: $F_{4,5}=5.76$, $P<0.05)$.

The above differences between selfed offspring, together with the lack of significant main effects of pollen load in the three-way analyses for fitness components not influenced by seed number (Fig. 2, Tables 2 and 3), (a)

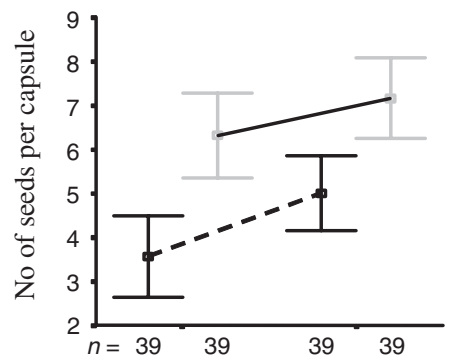

(c)

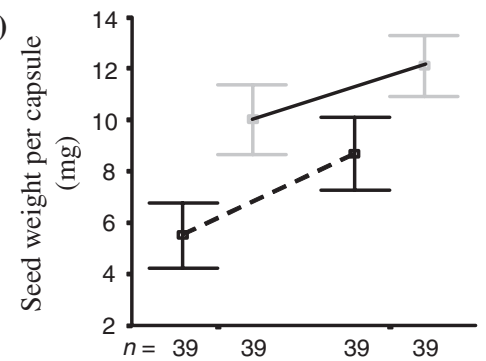

(e)

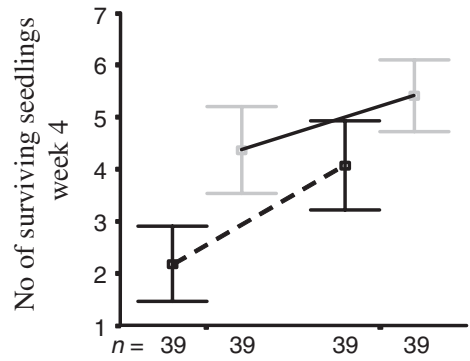

(g)

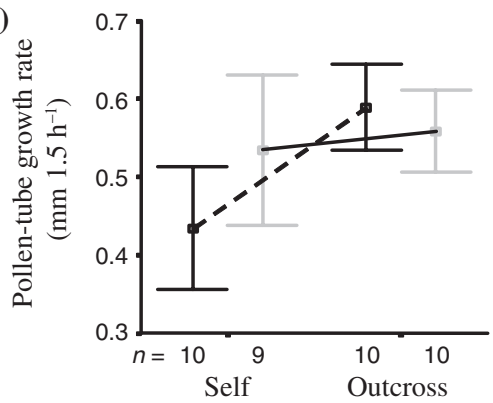

(b)

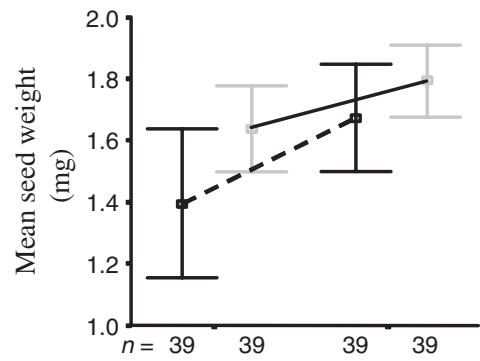

(d)

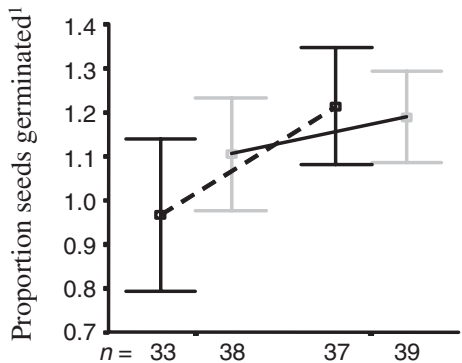

(f)

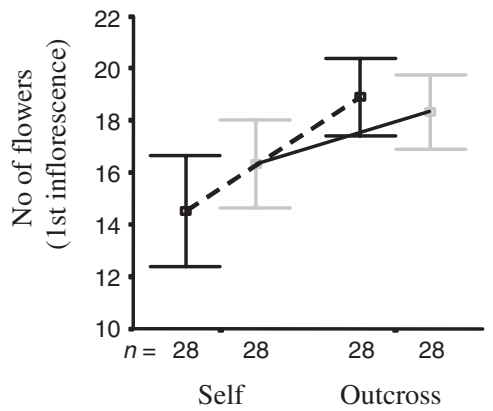

High pollen load Low pollen load - - - -
Fig. 2 (a-g) Graphs showing fitness of selfed and outcrossed offspring produced by low vs. high pollen-load treatments. Error bars indicate standard error. $N=$ number of maternal plants. All four types of crosses were performed on the same individual recipient.

${ }^{1}$ Arcsine transformed. 
Table 1 Two-way analyses of variance for fitness of offspring produced in crosses when self-pollen was deposited in small vs. large pollen loads on the stigma.

\begin{tabular}{|c|c|c|c|c|c|c|c|c|}
\hline Source of variation & d.f. & MS & F & $P$-value & d.f. & MS & $F$ & $P$-value \\
\hline & \multicolumn{4}{|c|}{ Mean seed weight (mg) } & \multicolumn{4}{|c|}{ Proportion seeds germinated* } \\
\hline Pollen load & 1 & 1.14 & 3.94 & 0.055 & 1 & 0.268 & 3.22 & 0.082 \\
\hline Mother & 38 & 0.473 & 1.64 & 0.066 & 37 & 0.300 & 3.59 & $<0.001$ \\
\hline \multirow[t]{2}{*}{ Error } & 38 & 0.289 & & & 32 & 0.0835 & & \\
\hline & \multicolumn{4}{|c|}{ Number of flowers (first inflorescence) } & \multicolumn{4}{|c|}{ Pollen-tube growth rate $(\mathrm{mm} / 1.5 \mathrm{~h})$} \\
\hline Pollen load & 1 & 121 & 2.77 & 0.106 & 1 & 0.0814 & 11.6 & 0.008 \\
\hline Mother & 27 & 57.2 & 1.29 & 0.260 & 9 & 0.0563 & 1.89 & 0.004 \\
\hline Pollen load $\times$ mother & 27 & 44.5 & 1.25 & 0.220 & 8 & 0.0071 & 1.31 & 0.303 \\
\hline Error & 75 & 35.5 & & & 17 & 0.0054 & & \\
\hline
\end{tabular}

Both types of pollinations (small vs. large pollen loads) were performed on the same mother plant.

*Arcsine-transformed.

Table 2 Three-way analyses of variance for early fitness components of offspring produced in crosses where self or outcross pollen (cross) was deposited in small or large pollen loads (pollen load) on the stigma.

\begin{tabular}{|c|c|c|c|c|c|c|c|c|c|c|c|c|c|c|c|c|}
\hline \multirow[b]{2}{*}{ Source of variation } & \multicolumn{4}{|c|}{ Number of seeds per capsule } & \multicolumn{4}{|c|}{ Mean seed weight $(\mathrm{mg})$} & \multicolumn{4}{|c|}{ Seed weight per capsule (mg) } & \multicolumn{4}{|c|}{ Proportion seeds germinated ${ }^{*}$} \\
\hline & d.f. & MS & $F$ & $P$-value & d.f. & MS & $F$ & $P$-value & d.f. & MS & F & $P$-value & d.f. & MS & $F$ & $P$-value \\
\hline Cross & 1 & 1.39 & 7.01 & 0.012 & 1 & 1.15 & 3.22 & 0.081 & 1 & 2.21 & 8.91 & 0.005 & 1 & 0.821 & 7.022 & 0.012 \\
\hline Pollen load & 1 & 3.89 & 35.6 & $<0.001$ & 1 & 1.80 & 9.30 & 0.004 & 1 & 4.79 & 35.2 & $<0.001$ & 1 & 0.996 & 3.058 & 0.088 \\
\hline Mother & 38 & 0.319 & 1.74 & 0.098 & 38 & 0.280 & 0.916 & 0.604 & 38 & 0.34 & 1.58 & 0.162 & 38 & 0.417 & 1.35 & 0.231 \\
\hline Cross $\times$ pollen load & 1 & 0.310 & 2.50 & 0.122 & 1 & 0.284 & 1.16 & 0.288 & 1 & 0.415 & 2.46 & 0.125 & 1 & 0.390 & 2.75 & 0.108 \\
\hline Cross $\times$ mother & 38 & 0.199 & 1.60 & 0.076 & 38 & 0.357 & 1.46 & 0.125 & 38 & 0.248 & 1.47 & 0.121 & 37 & 0.117 & 0.821 & 0.718 \\
\hline Pollen load $\times$ mother & 38 & 0.109 & 0.880 & 0.653 & 38 & 0.193 & 0.790 & 0.765 & 38 & 0.136 & 0.806 & 0.745 & 38 & 0.328 & 2.31 & 0.010 \\
\hline Error & 38 & 0.124 & & & 38 & 0.245 & & & 38 & 0.169 & & & 30 & 0.142 & & \\
\hline
\end{tabular}

All four types of crosses were performed on the same mother plant. Data were log-transformed.

*Arcsine-transformed.

Table 3 Three-way analyses of variance for later fitness components of offspring produced in crosses where self or outcross pollen (cross) was deposited in small or large pollen loads (pollen load) on the stigma.

\begin{tabular}{|c|c|c|c|c|c|c|c|c|c|c|c|c|}
\hline \multirow[b]{2}{*}{ Source of variation } & \multicolumn{4}{|c|}{ Number of surviving seedlings (week 4)* } & \multicolumn{4}{|c|}{ Number of flowers (first inflorescence) } & \multicolumn{4}{|c|}{ Pollen-tube growth rate $(\mathrm{mm} / 1.5 \mathrm{~h})$} \\
\hline & d.f. & MS & $F$ & $P$-value & d.f. & MS & $F$ & $P$-value & d.f. & MS & $F$ & $P$-value \\
\hline Cross & 1 & 3.12 & 14.6 & $<0.001$ & 1 & 1.00 & 7.72 & 0.010 & 1 & 0.126 & 6.39 & 0.032 \\
\hline Pollen load & 1 & 5.24 & 39.6 & $<0.001$ & 1 & 0.112 & 1.09 & 0.304 & 1 & 0.0313 & 4.25 & 0.067 \\
\hline Mother & 38 & 0.357 & 1.66 & 0.105 & 27 & 0.168 & 2.49 & 0.313 & 9 & 0.0469 & 1.89 & 0.158 \\
\hline Cross $\times$ pollen load & 1 & 0.586 & 4.47 & 0.041 & 1 & 0.516 & 3.13 & 0.088 & 1 & 0.0865 & 26.4 & 0.001 \\
\hline Cross $\times$ mother & 38 & 0.214 & 1.63 & 0.068 & 27 & 0.133 & 0.783 & 0.735 & 9 & 0.0200 & 5.98 & 0.011 \\
\hline Pollen load $\times$ mother & 38 & 0.132 & 1.01 & 0.489 & 27 & 0.105 & 0.615 & 0.894 & 9 & 0.0075 & 2.27 & 0.145 \\
\hline Cross $\times$ pollen load $\times$ mother & 38 & 0.131 & & & 27 & 0.170 & 2.82 & $<0.001$ & 8 & 0.0034 & 0.713 & 0.679 \\
\hline Error & & & & & 174 & 0.0603 & & & 54 & 0.0047 & & \\
\hline
\end{tabular}

All four types of crosses were performed on the same mother plant. Data were log-transformed.

*Number of surviving seedlings (week 4 ) $=$ number of seeds produced $\times$ seed germination $\times$ survival to week 4 .

indicate that pollen load has no detectable effect on the fitness of outcrossed offspring. One exception was the significant main effect of pollen load on mean seed weight with aborted capsules included (Table 2). This apparent effect, however, disappeared when analysing outcrossed seed weight excluding aborted capsules $\left(\bar{x}_{\text {low pollen load }}=1.765, \quad \mathrm{SE}=0.0633, \quad N=37\right.$; $\bar{x}_{\text {high pollen load }}=1.794, \quad \mathrm{SE}=0.0585, \quad N=39 ;$ two-way ANOvA; pollen load: $F_{1,38}=0.78, P=0.781$; mother: $\left.F_{38,38}=1.49, P=0.115\right)$. 


\section{Inbreeding depression in low vs. high pollen-load treatments}

Inbreeding reduced the values of all measured fitness variables (Fig. 2, Appendix 1). In six of the seven measured fitness components, this difference was significant (Tables 2 and 3). In the high-pollen load treatment, the magnitude of inbreeding depression was on average similar for variables expressed early vs. late in the life-cycle in the high pollen load treatment $\left(\delta_{\text {mean, }}\right.$ early $\left.=0.113, \delta_{\text {mean, late }}=0.113\right)$. In the low pollen load treatment, inbreeding depression increased by $24 \%$ from early to late variables in the low pollen load treatment $\left(\delta_{\text {mean, early }}=0.258, \delta_{\text {mean, late }}=0.320\right)$ (Appendix 1).

In accordance with our second prediction, the trend in means indicated less inbreeding depression in the high pollen-load treatment for all seven variables (Fig. 2, Appendix 1). In two of these fitness components, the total number of surviving seedlings in week 4 and pollentube growth rate, the significant cross-type-by-pollenload interaction indicated that the amount of inbreeding depression depended on the pollination intensity (Tables 2 and 3).

We conducted a test of overall significance based on our seven variables to ascertain the joint probability of getting all of the seven interactions in the predicted direction with at least two of the interactions being significant $(P=0.05$ in one case and $P<0.001$ in the other). The probability of obtaining a result at least this extreme, assuming $H_{0}$ is true, was $P<0.01$ (one-tailed binomial test). The interaction terms thus indicate a significant trend towards higher inbreeding depression in the low pollen-load treatment than in the high pollenload treatment. (The two only variables with significant interaction terms (total number of surviving seedlings and pollen-tube growth rate) were not significantly correlated (Pearson correlation; $r_{37}=0.261, P=0.108$ ). This should reduce the probability that we overestimated number of significant traits due to strong dependence between traits.) Indeed, average inbreeding depression (mean across components of fitness) was higher in the low pollen-load treatment $\left(\delta_{\text {mean }}=0.284\right)$ than in the high pollen-load treatment $\left(\delta_{\text {mean }}=0.113\right)$ (Wilcoxon signed ranks test, $T^{+}=28, N=7, \quad P<0.01$; Fig. 2, Appendix 1).

A multivariate analysis including all seven variables did not show any significant effects for any of the treatments or their interaction (within-subject MANova; cross: $F_{7,2}=1.93, P=0.384$, pollen load: $F_{7,2}=7.37$, $P=0.125$ cross $\times$ pollen load: $\left.F_{7,2}=3.92, P=0.218\right)$. When considering the variables expressed early vs. late in the life-cycle in separate manovas; however, we found a significant interaction term for the three late variables but not for the four early variables (Table 4). This suggests that the difference in inbreeding depression between high- and low-load treatments is more pronounced later in the life-cycle. On average, the magnitude of the difference in inbreeding depression between pollen-load treatments was $42 \%$ higher for fitness components measured later in the life-cycle compared with those measured early $\left(\delta_{\text {mean, early }}=0.144, \delta_{\text {mean, late }}=\right.$ 0.205) (Fig. 3).

\section{Allocation issues}

We were not able to detect effects of neighbour-flower pollination treatment on any component of offspring fitness (Table 5). It is thus unlikely that the decrease in inbreeding depression seen in the high pollen-load treatment is a result of differential allocation between flowers.

\section{Discussion}

Our hypothesis that pollen competition can reduce the negative effects of self-pollination led to two predictions (i) offspring produced by self-pollination should be of higher fitness when pollen competition is more intense; and (ii) measures of inbreeding depression should be reduced when pollen competition is more intense. In Collinsia heterophylla, a species with a mixed mating system, we detected higher fitness in offspring produced by larger self-pollen loads than in offspring produced by smaller self-pollen loads, which supports our first prediction. We also found an overall reduction of inbreeding depression when self-pollen competed more intensely for

Table 4 Doubly within-subject multivariance analyses for early and late fitness components of offspring produced in crosses when self pollen was deposited in small vs. large pollen loads on the stigma.

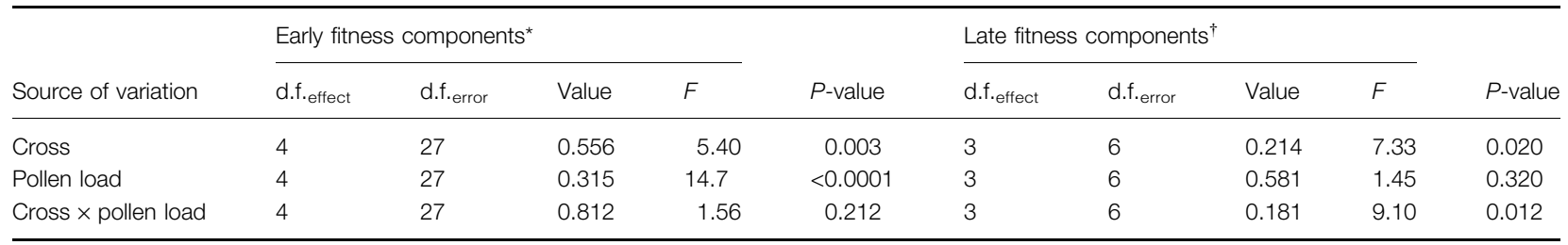

Both types of pollinations (small vs. large pollen loads) were performed on the same mother plant.

*Number of seeds per capsule, mean seed weight, seed weight per capsule, proportion seeds germinated.

${ }^{\dagger}$ Number of surviving seedlings (week 4), number of flowers (first inflorescence), pollen tube growth rate. 


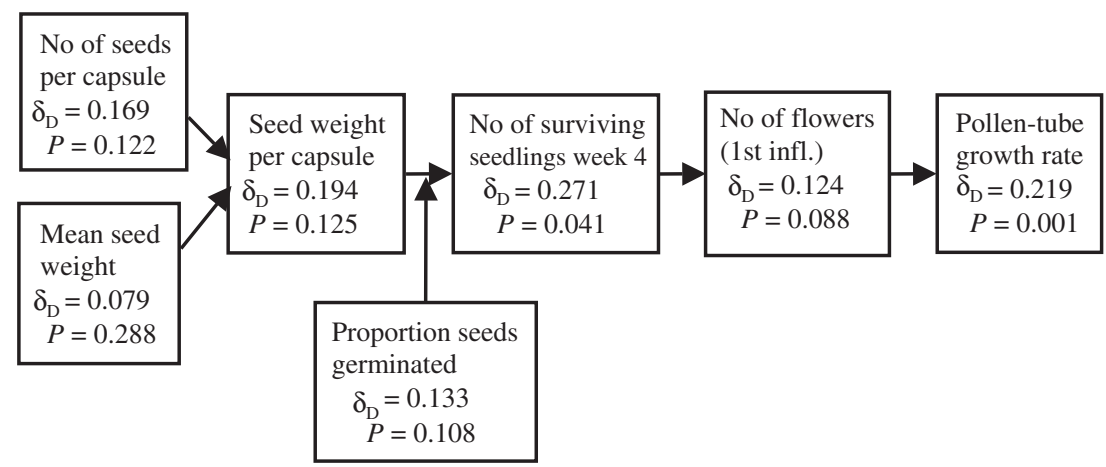

Fig. 3 Differences in the expression of inbreeding depression between high and low pollen-load treatments $\left(\delta_{\mathrm{D}}=\delta_{\text {low pollen load }}-\delta_{\text {high }}\right.$ pollen load) increases as the life-cycle proceeds. We considered seed traits and germination ability as variables expressed early in the life-cycle, whereas other traits were considered as variables expressed later in the life-cycle. $\delta$ denotes the difference in fitness between outcrossed and selfed progeny scaled by the value of outcrossed offspring. $P$-values refer to tests of crossing type by pollen-load interaction in a three-way general linear model (see Tables 2 and 3).

Table 5 Three-way analyses of variance for fitness of offspring produced from crosses in which self or outcross pollen was deposited in small or large pollen loads on the stigma.

\begin{tabular}{|c|c|c|c|c|c|c|c|c|}
\hline Source of variation & d.f. & MS & $F$ & $P$-value & d.f. & MS & $F$ & $P$-value \\
\hline & \multicolumn{4}{|c|}{ Number of seeds per capsule } & \multicolumn{4}{|c|}{ Mean seed weight (mg) } \\
\hline Cross & 1 & 51.1 & 6.12 & 0.015 & 1 & 1.73 & 5.81 & 0.017 \\
\hline Pollen load & 1 & 237 & 28.3 & $<0.001$ & 1 & 1.26 & 4.23 & 0.042 \\
\hline Neighbour & 3 & 14.1 & 1.69 & 0.173 & 3 & 0.133 & 0.447 & 0.720 \\
\hline Cross $\times$ pollen load & 1 & 3.34 & 0.400 & 0.528 & 1 & 0.113 & 0.379 & 0.539 \\
\hline Cross $\times$ neighbour & 3 & 2.82 & 0.337 & 0.798 & 3 & 0.472 & 1.58 & 0.196 \\
\hline Pollen load $\times$ neighbour & 3 & 2.36 & 0.285 & 0.838 & 3 & 0.224 & 0.751 & 0.523 \\
\hline Cross $\times$ pollen load $\times$ neighbour & 3 & 3.29 & 0.394 & 0.757 & 3 & 0.340 & 1.14 & 0.335 \\
\hline \multirow[t]{2}{*}{ Error } & 140 & 8.35 & & & 140 & 0.298 & & \\
\hline & \multicolumn{4}{|c|}{ Seed weight per capsule (mg) } & \multicolumn{4}{|c|}{ Proportion seeds germinated* } \\
\hline Cross & 1 & 269 & 15.6 & $<0.001$ & 1 & 0.999 & 6.12 & 0.015 \\
\hline Pollen load & 1 & 622 & 36.1 & $<0.001$ & 1 & 0.180 & 1.10 & 0.296 \\
\hline Neighbour & 3 & 27.7 & 1.61 & 0.191 & 3 & 0.176 & 1.08 & 0.360 \\
\hline Cross $\times$ pollen load & 1 & 10.9 & 0.635 & 0.427 & 1 & 0.224 & 1.37 & 0.243 \\
\hline Cross $\times$ neighbour & 3 & 4.01 & 0.233 & 0.873 & 3 & 0.166 & 1.02 & 0.387 \\
\hline Pollen load $\times$ neighbour & 3 & 7.83 & 0.455 & 0.714 & 3 & 0.185 & 1.13 & 0.338 \\
\hline Cross $\times$ pollen load $\times$ neighbour & 3 & 5.88 & 0.341 & 0.795 & 3 & 0.289 & 1.77 & 0.155 \\
\hline \multirow[t]{2}{*}{ Error } & 140 & 17.2 & & & 131 & 0.163 & & \\
\hline & \multicolumn{4}{|c|}{ Number of surviving seedlings (week 4) $\dagger$} & \multicolumn{4}{|c|}{ Number of flowers (first inflorescence) } \\
\hline Cross & 1 & 85.2 & 14.4 & $<0.001$ & 1 & 219 & 11.2 & 0.001 \\
\hline Pollen load & 1 & 123 & 20.7 & $<0.001$ & 1 & 25.9 & 1.32 & 0.253 \\
\hline Neighbour & 3 & 8.92 & 1.51 & 0.216 & 3 & 33.7 & 1.72 & 0.168 \\
\hline Cross $\times$ pollen load & 1 & 6.45 & 1.09 & 0.299 & 1 & 36.0 & 1.84 & 0.178 \\
\hline Cross $\times$ neighbour & 3 & 4.52 & 0.762 & 0.517 & 3 & 20.6 & 1.05 & 0.374 \\
\hline Pollen load $\times$ neighbour & 3 & 5.33 & 0.899 & 0.444 & 3 & 28.4 & 1.45 & 0.234 \\
\hline Cross $\times$ pollen load $\times$ neighbour & 3 & 2.20 & 0.370 & 0.774 & 3 & 28.3 & 1.44 & 0.235 \\
\hline Error & 140 & 5.93 & & & 96 & 19.6 & & \\
\hline
\end{tabular}

In order to assess the influence of allocation of maternal resources, each hand-pollinated flower was provided with a neighbour handpollinated with one of the four possible types of crosses.

*Arcsine-transformed.

$\dagger$ Number of surviving seedlings $($ week 4$)=$ number of seeds produced $\times$ seed germination $\times$ survival to week 4 .

access to ovules, providing firm support also for the second prediction. The most pronounced effects were seen in fitness components measured later in the life- cycle. Because we could not detect any effects of the type of cross performed on neighbouring flowers on offspring fitness, our result does not appear to be the consequence 
of differential allocation by the mother plant to certain offspring.

Reduction of inbreeding through pollen competition is seen in many species with self-incompatibility systems that rely on detection of incompatible alleles during pollen germination and pollen tube growth (Cruzan 1990; Lloyd \& Schoen 1992; Lush \& Clarke 1997; Stephenson et al. 2003). In this case, higher levels of pollen competition do not test the innate quality of the pollen genome, but rather allow assessment of how a certain pollen genome performs in a particular pistillate environment. Greater pollen competition can also increase the probability of sampling a genetically compatible sporophytic father (Paschke et al. 2002; Bernasconi et al. 2003).

Our study tested instead the hypothesis that competition among pollen from a single father in self-compatible species allows discrimination against pollen carrying recessive (in the diploid) deleterious alleles that are also found in the mother plant. We considered specifically self-pollen (or geitonogamy), although a similar effect should hold for deleterious alleles derived from any source that shares alleles with the maternal plant (Armbruster \& Rogers 2004). Our first prediction from this hypothesis was that intense pollen competition increases fitness of selfed offspring relative to weak pollen competition. In a study of Dalechampia scandens, mean seed mass and mean radicle-growth rate were greater when pollen competition was more intense (Armbruster \& Rogers 2004). This is consistent with our result in $C$. heterophylla. In addition to a significant effect on pollen tube growth rate, we found a marginally significant effect on mean seed weight and nonsignificant trends in the expected direction for the other two measured fitness components (seed germination and flower production).

Our second, and more critical prediction, was that inbreeding depression is reduced when pollen competition is increased. Inbreeding effects on all seven fitness components measured from early to late stages of the life-cycle were lower, on average, in offspring produced in the high pollen-load treatment $(11 \%)$ than in the low pollen-load treatment $(28 \%)$. When considered separately, the effect was significant in two of these traits.

Inbreeding depression in outcrossing species has often been shown to be large in both very early life stages (e.g. during seed maturation) and very late life stages (e.g. during growth and reproduction), whereas in more selfing species inbreeding depression is large generally only in late life stages (Husband \& Schemske 1996). This supports the hypothesis that early-acting inbreeding depression is caused by recessive lethals, whereas later effects are caused by weakly deleterious alleles that are more difficult to purge from the gene pool (Lande $\delta$ Schemske 1985; Charlesworth \& Charlesworth 1987; Charlesworth et al. 1990). In four populations of C. heterophylla, inbreeding depression ranged from $5 \%$ to
$40 \%$ and was most noticeable in very early and very late traits (Mayer et al. 1996), indicating presence of alleles with different degrees of deleterious effects. In our study, inbreeding depression (calculated as the average of the two pollen load treatments) was $13-33 \%$, which is of comparable value as, but slightly narrower range than in the previous study. For the large pollen-load treatment, inbreeding depression was on average very similar for fitness components expressed at different stages of the life-cycle, whereas for the small pollen-load treatment the expression of inbreeding depression appeared to increase slightly at later stages. Even though we were not able to explicitly test the relationship between the magnitude of inbreeding depression and stage of the life-cycle due to dependence of variables and life-cycle stages, the evaluated difference in means do not support a strong relationship. We did not, however, measure all late fitness traits, such as seed production in offspring. On the other hand, the difference in inbreeding depression between high and low pollen loads was most pronounced in late life-stages: number of surviving seedlings and pollen-tube growth rate in vitro. The former trait was, however, an integrative measure of multiple stages in the life-cycle from very early to later, i.e. seed production, germination and initial survival. Pollen performance of the offspring was strongly affected, with inbreeding effects nearly absent in the high pollen-load treatment. This suggests that pollen competition may have strongest effects on traits expressed in the gametophytic stage. Alternatively, pollen performance may be a more sensitive indicator of plant vigour than most sporophytic traits. Indeed, studies in Viola tricolor indicated that pollen performance was less affected by random environmental effects in the greenhouse than were sporophytic traits (Lankinen 2000).

To achieve pollen-load treatments of sufficient biological difference (see Mitchell 1997), we used a relatively small number of pollen grains in the low pollen load. For this reason, some of the differences seen in the number of seeds produced between treatments are probably an effect of pollen limitation. Higher numbers of seeds per capsule leads to more competition between seeds. It has been shown that the amount of inbreeding depression can be increased by competition between plants (Schmitt \& Ehrhardt 1990; Wolfe 1993) and between seeds (sibling competition) (Donohue 1998). Thus, if sibling competition affected the expression of inbreeding depression in this study, the effect should have been larger in the high pollen-load treatment. This effect would result in our study underestimating the reduction of inbreeding depression caused by intense pollen competition.

Under natural conditions, most pollen loads deposited by pollinators probably contain a mixture of pollen from different individuals (Snow 1994). For this reason, we chose to use a mixture of three donors as our outcross pollen source. This might have led to a higher probability of ovules being fertilized by a genetically superior father 
in the high pollen-load treatment (a genetic 'sampling effect', Paschke et al. 2002; Bernasconi et al. 2003; but cf. traditional studies of pollen competition, e.g. Winsor et al. 1987; Quesada et al. 1993). If this effect is important, it would simply generate larger differences between high and low loads when outcrossed than when selfed. However, we generally obtained the reverse result, suggesting that sampling of superior alleles was not the main cause of the pollen-competition effect. Indeed, if the sampling effect occurred, it would inflate the inbreeding depression measured under high pollen loads, either cancelling out or reversing the predicted trend toward greater inbreeding depression under low pollen loads, and hence reducing the support for our hypothesis.

When the intensity of pollen competition is adjusted by varying pollen-load size, hormonal consequences of heavy versus light pollen loads may influence offspring fitness and create problems for interpretation (Charlesworth 1988; Walsh \& Charlesworth 1992). Offspring produced under high pollen-load treatments might thus be of higher quality due to maternal allocation of resources in response to differences in hormone levels. However, our experiment estimating allocation effects indicated no significant influence of differential allocation of resources between flowers in this species. We thus judge it unlikely that the results seen in this study are a consequence of differential maternal provisioning.

Interestingly, the hypothesis that pollen competition might reduce inbreeding depression by purging deleterious alleles is similar to a suggestion found in the zoological literature. It has been argued that inbreeding depression might be low in systems with haplo-diploid sex determination (e.g. hymenoptera), because the haploid portion of the life cycle (males) is expected to purge deleterious alleles and thereby reduce inbreeding depression (Bruckner 1978; Werren 1993; Antolin 1999). Under partial dominance, the haploid males should express more of the recessive genetic load, leading to purging of genetic load. There is some evidence supporting this hypothesis (Henter 2003).

Our finding that competition among self-pollen may play a role in moderating inbreeding depression has several important implications. First, to be able to estimate inbreeding depression accurately, pollination intensity should be controlled (see also discussion in Armbruster \& Rogers (2004). Secondly, these results suggest an additional source of selection for traits that promote pollen competition. Rather than being of significance for the ability to sort among sporophyte fathers of different genetic quality or compatibility (reviewed in Mulcahy \& Mulcahy 1987; Willson 1994; Skogsmyr \& Lankinen 2002), such traits could evolve in response to selection generated by inbreeding depression in species with mixed mating systems. Such an adaptation should not be surprising, since plants with mixed mating systems frequently have genetic loads and consequently experience inbreeding depression when they occasionally, or regularly, self-pollinate (e.g. Johnston $\delta$ Schoen 1996; review by Husband $\delta$ Schemske 1996; see also Newman \& Pilson 1997; Chang \& Rausher 1999; Kephart et al. 1999; Routley et al. 1999; Rao et al. 2002). The possession of a feature that mitigates the negative effects of self-fertilization might, in turn, influence evolution of the mating system, because such traits should weaken selection against selfing.

In conclusion, we have shown that offspring produced by self-pollination had significantly lower fitness when pollen competition was less intense than when more. Furthermore, there was an overall reduction of inbreeding depression in greenhouse-grown Collinsia heterophylla when pollen competed for access to ovules. This effect was particularly pronounced in fitness components expressed later in the plant's life cycle. Our results are thus in accordance with both predictions of the hypothesis that pollen competition mitigates the negative effects of inbreeding in plants with mixed mating systems.

Reduction of inbreeding depression by pollen competition might lead to selection for traits that enhance pollen competition, which, in turn, might further influence the evolution of mating systems. The data provided here support this idea, but it deserves more empirical and theoretical exploration. In fact, a third prediction of the inbreeding-depression/pollen-competition hypothesis is yet to be tested: among self-compatible species, the greatest benefits of competition among self-pollen should be found in more outcrossing species (Armbruster $\delta$ Rogers 2004). This should hold because the reduction of inbreeding depression induced by pollen competition ought to vary with the genetic load, which should be greater in populations with histories of outcrossing (Husband \& Schemske 1996).

\section{Acknowledgements}

We wish to thank J. Maad for assistance in the greenhouse, J. Ripa for help with statistics, S. Anderson for helpful discussions and R. Härdling for comments on the text. The study was funded by European Science Foundation, the Knut and Alice Wallenberg Foundation, Marie Curie Individual Fellowship, the Norwegian Research Council, the National Science Foundation (Grant No. DEB-0324808), the Royal Swedish Academy of Sciences and the Swedish Research Council.

\section{References}

Adams, P., Helson, D.E., Yamada, S., Chamara, W., Jensen, R.G., Bohnert, H. \& Griffiths, H. 1998. Growth and development of Mesembryanthemum crystallinum (Aizoaceae). New. Phytol. 138: 171-190.

Antolin, M.F. 1999. A genetic perspective on mating systems and sex ratios of parasitoid wasps. Res. Pop. Ecol. 41: 29-37. 
Armbruster, W.S. \& Rogers, D.G. 2004. Does pollen competition reduce the cost of inbreeding? Am. J. Bot. 91: 1939-1943.

Armbruster, W.S., Debevec, E.M. \& Willson, M.F. 2002a. Evolution of syncarpy in angiosperms: theoretical and phylogenetic analyses of the effects of carpel fusion on offspring quantity and quality. J. Evol. Biol. 15: 657-672.

Armbruster, W.S., Mulder, C.P.H., Baldwin, B.G., Kalisz, S., Wessa, B. \& Nute, H. 2002b. Comparative analysis of late floral development and mating-system evolution in tribe Collinsiae (Scrophulariaceae S.L.). Am. J. Bot. 89: 37-49.

Bernasconi, G., Paschke, M. \& Schmid, B. 2003. Diversity effects in reproductive biology. Oikos. 102: 217-220.

Bernasconi, G., Ashman, T.-L., Birkhead, T.R., Bishop, J.D.D., Grossniklaus, U., Kubli, E., Marshall, D.L., Schmid, B., Skogsmyr, I., Snook, R.R., Taylor, D., Till-Bottraud, I., Ward, P.I., Zeh, D.W. \& Hellriegel, B. 2004. Evolutionary ecology of the prezygotic stage. Science. 303: 971-975.

Bernier, G., Havelange, A., Houssa, C., Petitjean, A. \& Lejeune, P. 1993. Physiological signals that induce flowering. Plant. Cell. 5: 1147-1155.

Bertin, R.I. 1990. Effects of pollination intensity in Campsis radicans. Am. J. Bot. 77: 178-187.

Bierzychudeck, P. 1981. Pollinator limitation of plant reproductive effort. Am. Nat. 117: 838-840.

Bruckner, D. 1978. Why are there inbreeding effects in haplodiploid systems? Evolution. 32: 456-458.

Burd, M. 1994. Bateman's principle and plant reproduction - the role of pollen limitation in fruit and seed set. Bot. Rev. 60: 83139.

Carr, S.G.M. \& Carr, D.J. 1961. The functional significance of syncarpy. Phytomorphology. 11: 249-256.

Chang, S.M. \& Rausher, M.D. 1999. The role of inbreeding depression in maintaining the mixed mating system of the common morning glory, Ipomoea purpurea. Evolution. 53: 1366-1376.

Charlesworth, D. 1988. Evidence for pollen competition in plants and its relationship to progeny fitness: a comment. Am. Nat. 132: 298-302.

Charlesworth, D. \& Charlesworth, B. 1987. Inbreeding depression and its evolutionary consequences. Annu. Rev. Ecol. Syst. 18: $237-268$.

Charlesworth, D. \& Mayer, S.S. 1995. Genetic variability of plant characters in the partial inbreeder Collinsia heterophylla (Scrophulariaceae). Am. J. Bot. 82: 112-120.

Charlesworth, D., Schemske, D.W. \& Sork, V.L. 1987. The evolution of plant reproductive characters; sexual versus natural selection. In: Sexual Selection: Testing the Alternatives (J.W. Bradbury \& M.B. Andersson, eds), pp. 317-335. Wiley, New York.

Charlesworth, B., Morgan, M.T. \& Charlesworth, D. 1990. Inbreeding depression, genetic load, and the evolution of outcrossing rates in a multilocus system with no linkage. Evolution. 44: 1469-1489.

Cheptou, P.O. \& Mathias, A. 2001. Can varying inbreeding depression select for intermediary selfing rate? Am. Nat. 157: 361-373.

Cruzan, M.B. 1990. Pollen-pollen and pollen-style interaction during pollen tube growth in Erythronium grandiflorum (Liliaceae). Am. J. Bot. 77: 116-122.

Delph, L.F., Weinig, C. \& Sullivan, K. 1998. Why fast-growing pollen tubes give rise to vigorous progeny: the test of a new mechanism. Proc. R. Soc. Lond. B Biol. Sci. 265: 935-939.
Donohue, K. 1998. Effects of inbreeding of traits that influence dispersal and progeny density in Cakile edentula var. Lacustris (Brassicaceae). Am. J. Bot. 85: 661-668.

Endress, P.K. 1982. Syncarpy and alternative modes of escaping disadvantages of apocarpy in primitive angiosperms. Taxon. 31: $48-52$.

Field, A. 2005. Discovering Statistics Using SPSS, 2nd edn. Sage Publications, London.

Fisher, R.A. 1941. Average excess and average affect of a gene substitution. Ann. Eugen. 11: 53-63.

Henter, H.J. 2003. Inbreeding depression and haplodiploidy: experimental measures in a parasitoid and comparisons across diploid and haplodiploid insect taxa. Evolution. 57: 1793-1803.

Herrera, C.M. 2002. Censusing natural microgametophyte populations: variable spartial mosaics and extreme fine graininess in winter-flowering Helleborus foetidus (Ranunculaceae). Am. J. Bot. 89: 1570-1578.

Herrera, C.M. 2004. Distribution ecology of pollen tubes: finegrained, labile spatial mosaics in southern Spanish Lamiaceae. New. Phytol. 161: 473-484.

Hill, T. \& Lewicki, P. 2006. Statistics: Methods and Applications. A Comprehensive Reference for Science, Industry and Mining. StatSoft Inc., Tulsa.

Hoekstra, F.A. \& Bruinsma, J. 1975. Respiration and vitality of binucleate and trinucleate pollen. Physiol. Plant. 34: 221-225.

Hormaza, J.I. \& Herrero, M. 1994. Gametophytic competition and selection. In: Genetic Control of Self-Incompatibility and Reproductive Development in Flowering Plants (E.G. Williams, A.E. Clarke $\delta$ R.B. Knox, eds), pp. 372-400. Kluwer, Dordrecht.

Hormaza, J.I. \& Herrero, M. 1996. Male gametophytic selection as a plant breeding tool. Sci. Hort. 65: 321-333.

Husband, B.C. \& Schemske, D.W. 1996. Evolution of the magnitude and timing of inbreeding depression in plants. Evolution. 50: 54-70.

Johnston, M.O. \& Schoen, D.J. 1994. On the measurement of inbreeding depression. Evolution. 48: 1735-1741.

Johnston, M.O. \& Schoen, D.J. 1996. Correlated evolution of self-fertilization and inbreeding depression: an experimental study of nine populations of Amsinckia (Boraginaceae). Evolution. 50: 1478-1491.

Kalisz, S. Vogler, D., Fails, B. Finer, M., Shepard, E., Herman, T., Gozales, R. 1999. The mechanism of delayed selfing in Collinsia verna (Scrophulariaceae). Am. J. Bot. 86: 12391247.

Kephart, S.R., Brown, E. \& Hall, J. 1999. Inbreeding depression and partial selfing: evolutionary implications of mixed-mating in a coastal endemic, Silene douglasii var. oraria (Caryophyllaceae). Heredity. 82: 543-554.

Khan, M.L., Bhuyan, P., Shanker, U. \& Todaria, N.P. 1999. Seed germination and seedling fitness in Mesua ferrea L. in relation to fruit size and seed number per fruit. Acta Oecologica. 20: 599-606.

Lande, R. \& Schemske, D.W. 1985. The evolution of selffertilization and inbreeding depression in plants. I. Genetic models. Evolution. 39: 24-40.

Lande, R., Schemske, D.W. \& Schultz, S.T. 1994. High inbreeding depression, selective interference among loci, and the threshold selfing rate for purging recessive lethal mutations. Evolution. 48: 965-978.

Lankinen, A. 2000. Effects of soil pH and phosphorus on in vitro pollen competitive ability and sporophytic traits in clones of Viola tricolor. Int. J. Plant. Sci. 161: 885-893. 
Lloyd, D.G. 1979. Some reproductive factors affecting the selection of self-fertilisation in plants. Am. Nat. 113: 67-79.

Lloyd, D.G. \& Schoen, D.J. 1992. Self- and cross-fertilization in plants. I. Functional dimentions. Int. J. Plant. Sci. 153: 341357.

Lush, W.M. \& Clarke, A.E. 1997. Observations of pollen tube growth in Nicotiana alata and their implications for the mechanism of self-incompatibility. Sex. Plant. Reprod. 10: 27-35.

Marshall, D.L. \& Ellstrand, N.C. 1986. Sexual selection in Raphanus sativus: experimental data on nonrandom fertilization, maternal choice, and consequences of multiple paternity. Am. Nat. 127: 446-461.

Mayer, S.S., Charlesworth, D. \& Meyers, B. 1996. Inbreeding depression in four populations of Collinsia heterophylla Nutt (Scrophulariaceae). Evolution. 50: 879-891.

Mitchell, R.L. 1997. Effects of pollen quantity on progeny vigor: evidence from the desert mustard Lesquella fendleri. Evolution. 51: 1679-1684.

Mulcahy, D.L. 1979. The rise of the angiosperms: a genecological factor. Science. 206: 20-23.

Mulcahy, D.L. \& Mulcahy, G.B. 1975. The influence of gametophytic competition on sporophytic fitness in Diantus chinensis.. Theor. Appl. Genet. 46: 277-280.

Mulcahy, D.L. \& Mulcahy, G.B. 1987. The effects of pollen competition. Am. Sci. 75: 44-50.

Mulcahy, D.L., Mulcahy, G.B. \& Searcy, K.B. 1992. Evolutionary genetics of pollen competition. In: Ecology and Evolution of Plant Reproduction (R. Wyatt, ed), pp. 25-36. Chapman and Hall, New York.

Neese, E.C. 1993. Collinsia. In: The Jepson Manual: Higher Plants of California (J.C. Hickman, ed), pp. 1024-1027. University of California Press, Berkeley, CA.

Newman, D. \& Pilson, D. 1997. Increased probability of extinction due to decreased genetic effective population size: experimental populations of Clarkia pulchella. Evolution. 51: 354-362.

Newson, V.M. 1929. A revision of the genus Collinsia. Botan. Gaz. 87: 260-301.

Paschke, M., Abs, C. \& Schmid, B. 2002. Effects of population size and pollen diversity on reproductive success and offspring size in the narrow endemic Cochlearia bavarica (Brassicaceae). Am. J. Bot. 89: 1250-1259.

Prinzie, T.P. \& Chmielewski, J.G. 1994. Significance of achene characteristics and within-achene resource allocation in the germination strategy of tetraploid Aster pilous var. pilosus (Asteraceae). Am. J. Bot. 81: 259-264.

Quesada, M., Winsor, J.A. \& Stephenson, A.G. 1993. Effects of pollen competition on progeny performance in a heterozygous cucurbit. Am. Nat. 142: 694-706.

Rao, G.-Y., Widén, B. \& Andersson, S. 2002. Patterns of inbreeding depression in a population of Brassica (Brassicaceae): evidence from family-level analyses. Biol. J. Linn. Soc. Lond. 76: 317-325.

Routley, M.B., Mavraganis, K. \& Eckert, C.G. 1999. Effect of population size on the mating system in a self-compatible, autogamous plant, Aquilegia canadensis (Ranunculaceae). Heredity. 82: 518-528.

Schemske, D.W. \& Lande, R. 1985. The evolution of selffertilisation and inbreeding depression in plants. II. Empirical observations. Evolution. 39: 41-52.

Schmitt, J. \& Ehrhardt, D.W. 1990. Enhancement of inbreeding depression by dominance and suppression in Impatiens capensis. Evolution. 44: 269-278.
Siegel, S. \& Castellan N.J., Jr 1988. Nonparametric Statistics for the Behavioral Sciences. McGraw-Hill Book Co., New York.

Skogsmyr, I. \& Lankinen, A. 2002. Sexual selection: an evolutionary force in plants? Biol. Rev. 77: 537-562.

Snow, A.A. 1982. Pollination intensity and potential seed set in Passiflora vitfolia. Oecologia. 55: 231-237.

Snow, A.A. 1994. Postpollination selection and male fitness in plants. Am. Nat. 144 (Suppl.), 69-83.

Sokal, R.R. \& Rohlf, F.J. 1995. Biometry, 3rd edn. W.H. Freeman and Co., New York.

SPSS, 1999. SPSS 11.0, Syntax Reference Guide. SPSS Inc., Chicago, IL.

STATISTICA, 2005. STATISTICA, 7.1. Statsoft Inc., Tulsa, OK.

Stephenson, A.G., Travers, S.E., Mena-Ali, J.I. \& Winsor, J.A. 2003. Pollen performance before and during the autotrophicheterotrophic transition of pollen tube growth. Philos. Trans. $R$. Soc. Lond. Biol. 358: 1009-1018.

Tsitrone, A., Duperron, S. \& David, P. 2003. Delayed selfing as an optimal mating strategy in preferentially outcrossing species: theoretical analysis of optimal age at first reproduction in relation to mate availability. Am. Nat. 162: 318-331.

Vogler, D.W. \& Kalisz, S. 2001. Sex among the flowers: the distribution of plant mating systems. Evolution. 55: 202-204.

Walsh, N.E. \& Charlesworth, D. 1992. Evolutionary interpretations of differences in pollen tube growth rates. Q. Rev. Biol. 67: $19-37$.

Werren, J.H. 1993. The evolution of inbreeding in a haploid organism. In: The Natural History of Inbreeding and Outbreeding (N.W. Thornhill, ed), pp. 42-94. University of Chicago Press, Chicago, IL.

Whittington, W.J. \& Fierlinger, P. 1972. The genetic control of time to germination in tomato. Ann. Bot. (Lond.). 36: 873-880.

Willson, M.F. 1994. Sexual selection in plants: perspective and overview. Am. Nat. 144 (Suppl.), 13-39.

Wilson, P., Thomson, M.L., Stanton, M.L. \& Rigney, L.P. 1994. Beyond floral batemania: gender bias in selection for pollination success. Am. Nat. 143: 283-296.

Winsor, J.A., Davis, L.E. \& Stephenson, A.G. 1987. The relationship between pollen load and fruit maturation and the effect of pollen load on offspring vigor in Cucurbita pepo. Am. Nat. 129: 643-656.

Wolfe, L.M. 1993. Inbreeding depression in Hydrophyllum appendiculatum: role of maternal effects, crowding, and parental mating history. Evolution. 47: 374-386.

\section{Supplementary material}

The following supplementary material is available for this article online:

Appendix S1. Inbreeding depression values, $\delta$, measured as the difference in fitness between outcrossed and selfed progeny scaled by the value of outcrossed offspring.

This material is available as part of the online article from http://www.blackwell-synergy.com

Received 8 February 2006; revised 7 August 2006; accepted 7 August 2006 